\title{
Could Metabolic Syndrome, Lipodystrophy, and Aging Be Mesenchymal Stem Cell Exhaustion Syndromes?
}

\author{
Eduardo Mansilla, ${ }^{1}$ Vanina Díaz Aquino, ${ }^{1}$ Daniel Zambón, ${ }^{2}$ Gustavo Horacio Marin, ${ }^{1}$ \\ Karina Mártire, ${ }^{1}$ Gustavo Roque, ${ }^{1}$ Thomas Ichim, ${ }^{3}$ Neil H. Riordan, ${ }^{3}$ Amit Patel, ${ }^{4}$ \\ Flavio Sturla, ${ }^{5}$ Gustavo Larsen, ${ }^{6,7}$ Rubén Spretz, ${ }^{6,7}$ Luis Núñez, ${ }^{8,9}$ Carlos Soratti, ${ }^{10}$ \\ Ricardo Ibar, ${ }^{10}$ Michiel van Leeuwen, ${ }^{11}$ José María Tau, ${ }^{1}$ Hugo Drago, ${ }^{5}$ and Alberto Maceira ${ }^{1}$ \\ ${ }^{1}$ Tissue Engineering, Regenerative Medicine and Cell Therapies Laboratory, CUCAIBA, Ministry of Health, Province of Buenos Aires, \\ 1900 La Plata, Argentina \\ ${ }^{2}$ Lipid Clinic, Division of Endocrinology, Hospital Clinic, 08036 Barcelona, Spain \\ ${ }^{3}$ Division of Endometrial Regenerative Stem Cells, Medistem Inc., San Diego, CA 92122, USA \\ ${ }^{4}$ Division of Cardiothoracic Surgery, University of Utah, Salt Lake City, UT 84132, USA \\ ${ }^{5}$ Division Skin Bank, Burns Hospital, Buenos Aires City, C1424BSD, Argentina \\ ${ }^{6}$ LNK Chemsolutions, Division of Nanotechnology, Lincoln, NE 68521, USA \\ ${ }^{7}$ Bio-Target, Division of Nanotechnology, NE 68339, USA \\ ${ }^{8}$ The University of Chicago, Division of Nanotechnology, Chicago, IL 60637, USA \\ ${ }^{9}$ Nanovogue Inc., Division of Intelligent Matrices, Chicago, IL 60126-2731, USA \\ ${ }^{10}$ INCUCAI, Presidency, Ministry of Health, 2250-C1428BAJ Buenos Aires, Argentina \\ ${ }^{11}$ Vrije Universiteit, Burns Division, 1081 HV Amsterdam, The Netherlands \\ Correspondence should be addressed to Eduardo Mansilla, edmansil@netverk.com.ar
}

Received 15 August 2010; Accepted 22 March 2011

Academic Editor: Jozef Bartunek

Copyright () 2011 Eduardo Mansilla et al. This is an open access article distributed under the Creative Commons Attribution License, which permits unrestricted use, distribution, and reproduction in any medium, provided the original work is properly cited.

One of the most important and complex diseases of modern society is metabolic syndrome. This syndrome has not been completely understood, and therefore an effective treatment is not available yet. We propose a possible stem cell mechanism involved in the development of metabolic syndrome. This way of thinking lets us consider also other significant pathologies that could have similar etiopathogenic pathways, like lipodystrophic syndromes, progeria, and aging. All these clinical situations could be the consequence of a progressive and persistent stem cell exhaustion syndrome (SCES). The main outcome of this SCES would be an irreversible loss of the effective regenerative mesenchymal stem cells (MSCs) pools. In this way, the normal repairing capacities of the organism could become inefficient. Our point of view could open the possibility for a new strategy of treatment in metabolic syndrome, lipodystrophic syndromes, progeria, and even aging: stem cell therapies.

\section{Introduction}

Metabolic syndrome is recognized today as one of the most important causes of morbidity and mortality in the modern world $[1,2]$. Metabolic syndrome is characterized by a variety of symptoms such as obesity with abundant visceral fat, dyslipidemia, carbon hydrates intolerance, insulin resistance and eventually type 2 diabetes, development of arterial hypertension, fat liver disease, sleep apnea, and atherosclerosis with high incidence of myocardial infarction and stroke [3-5]. Although many and different preventive and pharmacological strategies have been applied during the last two decades, the mortality rate of metabolic syndrome continues to be unacceptably high $[6,7]$. Then, the central point to consider would be that its critical physiopathogenic pathway has not been discovered yet. As a consequence, it has not been possible so far to design the most appropriate and definitive treatment for it. In this context, it is essential 
to generate a new framework that could explain the main mechanism of this syndrome development and persistence, allowing then to an effective and enduring cure.

\section{The Cellular Perspective}

We propose to consider all these issues from a cellular perspective, which could open a pioneering vision for the interpretation and treatment of complex clinical situations such as metabolic syndrome, between many others. It is not generally known that metabolic syndrome is linked to lipodystrophies as much as to obesity $[8,9]$. Congenital lipodystrophies (Berardinelli Seip syndrome, EmeryDreifuss muscular dystrophy, and Dunnigan-type familial partial lipodystrophy) and acquired lipodystrophies (HIVassociated lipodystrophy, cachexia associated with neoplasias, among others) are characterized indeed by the loss of adipose tissue and also by insulin resistance, fat liver disease, dyslipidemia with hypertriglyceridemia, and many other manifestations of the metabolic syndrome [1012] (Figure 1). In lipodystrophies, there is a continuous and severe loss of adipocytes by apoptosis leading to an inadequate metabolism of free fatty acids, generating severe organic consequences like lipotoxicity, which are closely related to development of metabolic syndrome $[13,14]$. On the other hand, in obesity, there is also cellular damage but mainly produced by lipotoxicity, directly related to an excessive ingestion of calories and fats from the diet and by an overwhelmed system incapable of properly metabolizing them [15]. In this situation, hypertrophy and/or hyperproliferation of adipocytes would be the only physiological alleviating mechanism only for a short period of time [16]. Metabolic syndrome, lipodystrophies, and even progeria and aging could be more accurately explained by cellular mechanisms rather than by molecular and biochemical ones.

\section{The Emergence of Adipocytes and the Perpetuation of Fat}

The adipose tissue comprises one of the largest organs in the body. Even lean adult men and women have at least $3.0-4.5 \mathrm{~kg}$ of adipose tissue, and in individuals with severe obesity, adipose tissue can constitute $45 \mathrm{~kg}$ or more of body weight. The adipose organ is complex, with multiple depots of white adipose tissue involved in energy storage, hormone (adipokine) production, and local tissue architecture, as well as small depots of brown adipose tissue, required for energy expenditure to create heat (nonshivering thermogenesis) [17]. The potential to acquire new fat cells appears to be a permanent phenomenon in both animals and humans, before or after birth [18]. Therefore, proliferative adipocyte precursor cells must stand as ready to respond to increased demand for energy storage [19]. How adipocytes (fat cells) develop and where their progenitors come from, and for how long and under which circumstances they can provide sufficient support for more fat to be formed while maybe participating in other body functions, is a fundamental biological question with important ramifications for human health and disease. An increase in fat mass associated with obesity could only result from recruitment and differentiation of adipocyte progenitor cells. Despite the recognition of distinct progenitor populations in adipose tissue, it has been assumed that all white adipocytes and their progenitors arise solely from cells of mesenchymal origin [20]. Accumulating evidence suggests that adipocyte progenitors could proceed from bone marrow cells of mesenchymal lineage $[21,22]$. Visceral adipose tissue associated with Metabolic Syndrome is a chemotactic niche, whereby mesenchymal stem cells can home to and differentiate into adipocytes to perpetuate its tissue formation [20]. The intertwined epidemics of obesity and diabetes demands an improved understanding of adipocytes and its progenitor cell biology. Adipose tissue mass can expand throughout adult life. Mesenchymal stem cells with a multilineage potential have been isolated from human adipose tissue. Their adipocyte differentiation has been thoroughly studied, and differentiated cells exhibit the unique feature of human adipocytes [22]. One paradigm supports the notion that adipocytes arise from mesenchymal stem cells (MSCs) by a sequential pathway of differentiation. When triggered by appropriate developmental cues, MSCs become committed to the adipocyte lineage. A better knowledge of MSC's differentiation pathways will surely allow the design of new therapeutic strategies for reconstruction of damaged tissues and for the control or prevention of risks associated with obesity in humans $[17,23,24]$. This process can be divided into two related steps: (1) determination, when multipotent mesenchymal stem cells commit to preadipocytes (these cells exhibit similar morphology compared to stem cells, but they are committed to the adipogenic lineage and are no longer able to transform into osteoblasts, myocytes, or chondrocytes and (2) differentiation, when preadipocytes become mature fat cells. This mechanism is tightly regulated at a molecular level by several transcription factors. Several members of the MAPKinases, bone morphogenic proteins, winglesstype MMTV integration site (Wnt) proteins, hedgehogs, delta/jagged proteins, fibroblastic growth factors, insulin, insulin-like growth factors, and transcriptional regulators of adipocyte and osteoblast differentiation including peroxisome proliferator-activated receptor-gamma and runtrelated transcription factor 2 (Runx2) families have been shown to modify the steps of adipogenesis [23]. Despite the well-documented differences in the metabolic and biochemical properties among anatomically distinct depots of fat, the visceral fat contains adult mesenchymal stem cells with developmental potential similar to those isolated from subcutaneous fat in humans [21]. Thus, adipose precursors cells consist of fibroblast mesenchymal like multipotential stem cells generally termed adipose-derived stem cells (ASCs) and exhibit preadipocyte characteristics. They can be isolated, propagated in vitro, and induced to differentiate into adipocytes [25-27]. The adipose vasculature appears to function as a progenitor niche and may provide signals for adipocyte development. Stromal-vascular cells of adipose tissue are adipose precursor and its differentiation in vitro correspond to the sequence: adipoblast (unipotential cells), 


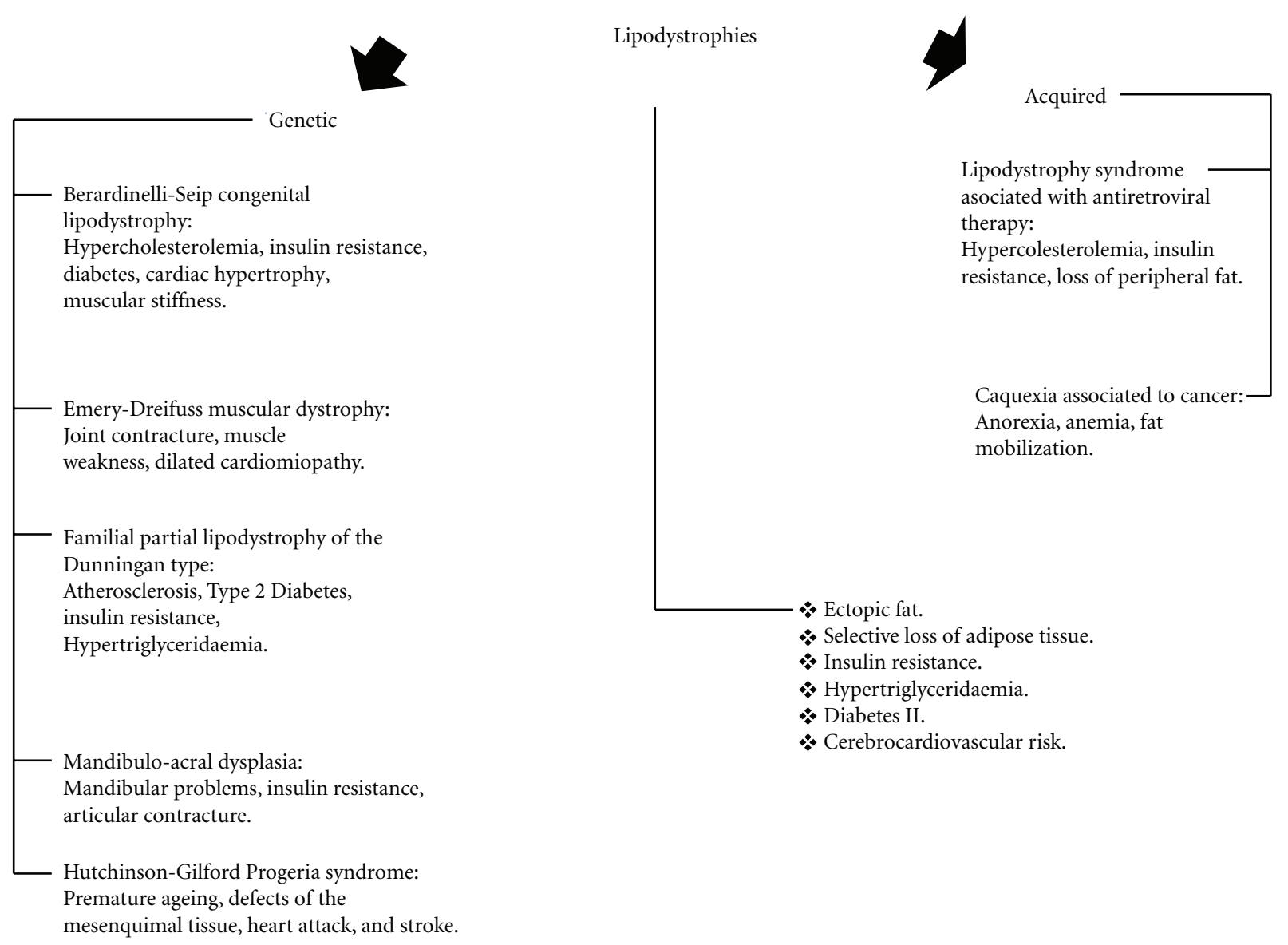

FIGURE 1: Lipodistrophic syndromes.

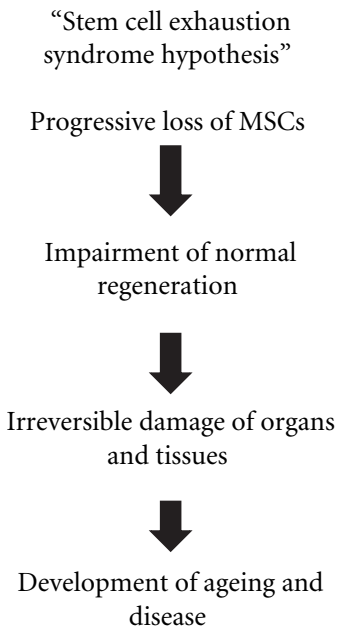

FIGURE 2: Stem cell exhaustion syndrome hypothesis.

commitment preadipose cell (preadipocyte), terminal differentiation immature adipose cell, and terminal differentiation mature adipose cell (adipocyte) [28]. Also bone marrow progenitor- (BMP-) derived adipohematopoietic cells via the myeloid lineage have been mentioned as the adipocyte progenitors cells. In any way, these BMP-derived adipocytes could accumulate with age and occur in higher numbers in visceral than in subcutaneous fat, and in female versus male mice. BMP-derived adipocytes may, therefore, account in part for adipose depot heterogeneity and detrimental changes in adipose metabolism and inflammation with aging and adiposity [29]. The development of obesity not only depends on the balance between food intake and caloric utilization but also on the balance between white adipose tissue (WAT), which is the primary site of energy storage, and brown adipose tissue (BAT), which is specialized for energy expenditure. Considerable evidence now supports the view that BAT and WAT are distinct organs. In addition, some sites of white fat storage in the body are more closely linked than others to the metabolic complications of obesity, such as diabetes. White areas contain a variable amount of brown adipocytes, and their number varies with age, strain, and environmental conditions. Recent data have stressed the plasticity of the adipose organ in adult animals. Indeed, under peculiar conditions fully differentiated, white adipocytes can transdifferentiate into brown adipocytes, and vice versa. The ability of the adipose organ to interconvert its main cytotypes in order to meet changing metabolic needs is highly pertinent to the physiopathology of obesity and related to therapeutic strategies. The differentiation between 


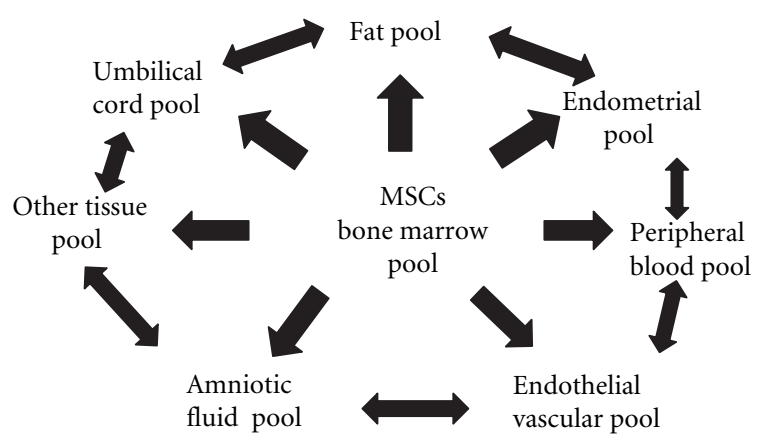

FIGURE 3: Mesenchymal stem cells pools as a coordinated network.

white adipocyte and brown adipocyte lineages occurs in the earliest steps of the fetal development, and both phenotypes are acquired independently [30-33]. Fetal mesenchymal stem cells (fMSCs) can differentiate into brown and white adipocytes. The expression of key adipocyte regulators and markers during differentiation is similar to that in other human and murine adipocyte models, including induction of PPAR $\gamma 2$ and FABP4. The preadipocyte marker, Pref1 , is induced early in differentiation and then declines markedly as the process continues, suggesting that fMSCs first acquire preadipocyte characteristics as they commit to the adipogenic lineage, prior to their differentiation into mature adipocytes. After adipogenic induction, some stem cell isolates differentiated into cells resembling brown adipocytes and others into white adipocytes. Importantly, these cells exhibited elevated basal UCP-1 expression. Thus, fMSCs represent a useful in vitro model for human adipogenesis and provide opportunities to study the stages prior to commitment to the adipocyte lineage. They also offer invaluable insights into the characteristics of human brown fat [34].

\section{The Stem Cell Exhaustion Syndrome}

In order to self-repair, living organisms have stem cells in central and peripheral locations which can be attracted to sites of injured tissues by "alarm signals" [35]. In this way, these cells proliferate, migrate, and accumulate in those damaged sites [36]. If this situation of "alarm" perpetuates, stem cells could be permanently exhausted from their original locations leading to irreversible disease (Figure 2). Basically, it could be a matter of stem cell quantity and effective availability mainly related to production and consumption in a certain time point when active regeneration is needed. The expected consequences of this situation could be the lack of an appropriate number of stem cells for further tissue replacement and regeneration and eventually the development of disease and aging. It is not completely clear yet if there could be a possible established, coordinated network or a dynamic connection as well as a biological equilibrium between all of these locations. This could finally lead to a constant traffic and exchange of stem cells among all of them in order to provide a perfect mechanism of stem cell provision and replenishment for normal repairment and the perpetuation of complex living organisms on Earth. Although there is not a definitive evidence for a possible alteration of this dynamic, involving an abnormal stem cell depletion kinetic mechanism, it could be interesting to hypothesize about these cell pathways that could open a new era of understanding of disease and therapeutics. For example, we could think that any alteration of this stem cell homeostasis by constant and repetitive trauma, physical hyperactivity, and chronic disease could provoke a persistent disequilibrium inside all these reserve locations. This could promote an irreversible and premature stem cell exhaustion syndrome (SCES), being impossible then for the organism to self-repair and survive.

\section{MSCs: The Exhausted Stem Cell?}

Tissue and organ damage is constantly taking place in living organisms as a consequence of life itself, diseases, and trauma [37]. A decrease in the endogenous pools of progenitor cells, such as CD34 stem cells and endothelial progenitor cells (EPCs), has been demonstrated to contribute and accelerate the course of cardiovascular disease seen in metabolic syndrome. Several experimental studies have indicated a relevant contribution of these progenitor cells in reendothelization at sites of endothelial injury and in neovascularization at sites of ischaemia. The extent of the EPC pool negatively correlates with cumulative indexes of cardiovascular event risk, such as the Framingham risk score, and multiple risk factors act synergically in reducing EPC, increasing the risk for cardiovascular disease [3840]. Mesenchymal stem cells (MSCs) are probably the most important specialized repairing cells $[41,42]$. MSCs are adult stem cells with the capacity and potential of differentiation towards multiple tissue lineages such as adipose, bone, muscle, cartilage, skin, nervous system, and endothelium between many others $[43,44]$. They can produce a large variety of growth factors, and they have immunomodulatory properties that allow them to avoid the immune rejection response when transplanted intra- and even interspecies $[45,46]$. Although they reside mainly in the bone marrow (BM) and share with hematopoietic stem cells a similar microenvironment, they are phenotypically very different to them $[47,48]$. Also, during the last few years, it has been possible to isolate them from many other sites, like dental pulp, endometrium, peripheral blood, umbilical cord, adipose tissue, and even amniotic fluid $[49,50]$. Recent studies have also obtained MSCs from vascular vessels, being proposed that they could be found in the perivascular space throughout the whole body [51]. We will refer to all these precise anatomical locations where MSCs are stored as "MSCs pools," being the bone marrow the central MSCs pool and the others the peripheral ones (Figure 3 ). In these pools, MSCs usually stay in a quiescent and undifferentiated state until they are called to proliferate and mobilize by "alarm signals" such as proinflammatory cytokines like INF- $\alpha$ and IL-6 among others and many growth factors like GM-CSF [52-54]. Then, it is possible to think that because of the supercaloric food intake of obese patients with metabolic syndrome, a high 


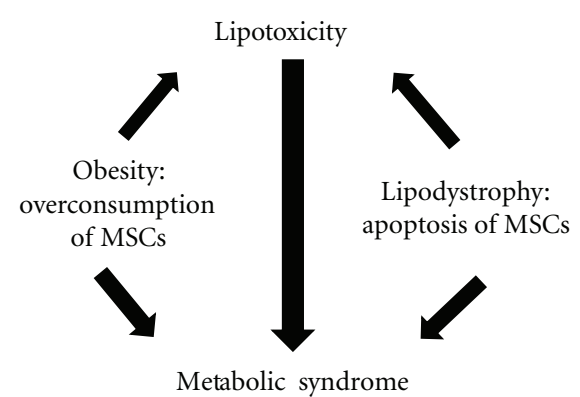

FIgURE 4: Metabolic syndrome in obesity and lipodistrophy.

degree of proinflammatory substances could be produced and released in different microenvironments, specially the abdominal visceral fat one [55]. This could only lead to the perpetuation of this inflammatory state with a constant emission of "alarm signals," proliferation, mobilization, and finally an endless sequestration of MSCs into the visceral fat depot [56]. Recently, a research group has found evidence of this adipotaxis phenomenon in an animal model, where the MSCs of the BM migrated attracted to the fat depot by TNF-Alfa [57]. This mechanism could give support to the idea of an abnormal migration of MSCs, in patients with metabolic syndrome, leading at some point to the mentioned irreversible impairment of tissue repairment (Figure 4).

\section{MSCs Exhaustion and Aging}

Metabolic syndrome incidence increases with the advancement of age [58, 59]. Human aging is another example of organ and tissue deterioration that could have a stem cell deficiency, very similar to that observed in metabolic syndrome. The classical human model of premature aging is the Hutchinson-Gilford Progeria syndrome (HGPS) [60, 61]. Progeria manifestations start at 18 months of age approximately, with alopecia, skeletal defects, distinctive facial appearance, and lipodystrophy $[62,63]$. These patients also develop dyslipidemia and arterial hypertension [64]. Almost all of them have atherosclerosis as well as cardio and cerebrovascular disease by 13 years of age with premature death [65]. Progeria is produced by a mutation in the gene that codes for the protein of nuclear membrane Lamin A [66]. This mutation makes MSCs sensitive to apoptosis [67]. This issue could explain why many tissues of mesenchymal origin are specially affected in these patients [68]. HGPS is a pathology of segmental nature, in which the different tissues and organs exposed to a variety of different conditions such as mechanical stress are affected differently [69]. Tissues with different turnover rates would require a different number of stem cells for replacement. For example, hair and muscle cells should need to be replenished by MSCs more frequently than central nervous system ones [70]. In patients with progeria, stem cells are at least in principle irreversible damaged, suffering from early apoptosis [71]. Young peripheral tissues, especially those in continuous turnover, are probably more restricted of new replacing stem cells. In this way, progeria patients usually suffer as it was said from alopecia, vascular

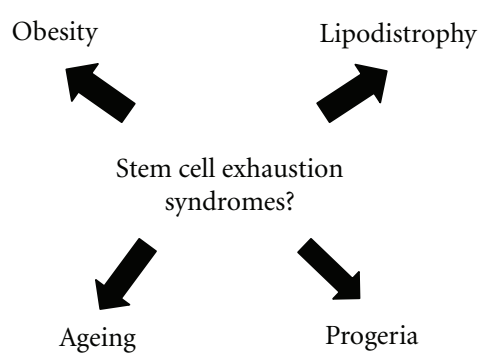

FIgURE 5: Pathologies propably caused by a stem cell exhaustion syndrome.

damage, and premature death by myocardial infarction or stroke $[72,73]$. On the other hand, tissues with a slower turnover rate, such as central nervous system, suffer less notorious and more prolonged deterioration. Their pathology is not seen at all in progeria patients as they do not live long enough to be able to evidence damage of these tissues $[74,75]$. An excessive cell turnover without the possibility of a concomitant cell replenishment mechanism, could lead to a slow but progressive deterioration usually seen in living organisms and known as "normal ageing" [76]. From this perspective, all these phenomena could be very similar to those observed in metabolic syndrome, lipodystrophic syndromes, and progeria. There is evidence that TNF-alfa progressively increases with age in adipose tissue which also rearranges itself and becomes dysfunctional with an inadequate response to insulin and increased production of cytokines [77]. This de novo proinflammatory generated environment is followed by a highly sensitive state of adipocytes to lipotoxicity [78] and a possible sequestration of a large number of MSCs especially from the BM central pool, which at the same time becomes progressively exhausted with the passing of time. "Normal aged" BM can be seen infiltrated by fat depots with a very reduced number of MSCs, having the significance of this phenomenon still unknown to date [79] (Figure 5). In other words, all these clinical situations could be explained by a stem cell exhaustion syndrome (SCES) causing an impaired regenerative potential.

\section{The New Paradigm: Cell Therapy}

Stem cell restoration has already demonstrated therapeutic activities in certain systems. For example, it is known that after a stroke, endogenous stem cells are mobilized from the bone marrow in an attempt to heal the damaged neural tissue. Most interestingly, a recent study demonstrated that stroke patients who exhibit a high level of stem cell mobilization have better functional outcomes as opposed to patients with a lower mobilization [80]. Restoration of stem cell function has been studied in aging, in which senescent endothelium can be replaced by the addition of young endothelial progenitor cells. In animal models, this has been shown to "reverse" endothelial aging [81]. In patients administered GM-CSF in order to mobilize autologous bone marrow stem cells, improvements in endothelial function, 
as demonstrated by increased responsiveness of flow, have also been proven [82]. More "natural" means of mobilizing stem cells into the periphery include the use of food supplements. It has been reported that administration of "StemEnhance," a commercially available food supplement made from cyanobacterium Aphanizomenon flos-aquae, induces a transient $18 \%$ increase in circulating CD34 cells over the period of one hour after consumption [83]. Another commercially available food supplement, "StemKine," has been demonstrated to induce a $50-100 \%$ increase of CD34 and endothelial progenitor cells in circulation for the observation period of over 2 weeks [84]. Given that similar increases in circulating stem cells have been associated with "health-inducing" activities such as exercise [85] and smoking cessation [86], it may be rationale to examine therapeutic effects of these supplements using functional endpoints. One critical point to consider is whether mobilization would accelerate exhaustion of stem cells in the bone marrow compartment. Given expression of telomerase in the bone marrow hematopoietic stem cells and its ability to be modulated by nutritional [87] and antioxidant interventions [88], it appears that this problem may be at least theoretically addressed. If a stem cell depletion kinetic abnormality (MSCs exhaustion syndrome) is true, then a stem cell therapy approach could be feasible. For instance, ex vivo expansion and reinfusion of MSCs from the patient's own or from allogeneic donors, as evidence shows that MSCs are not immunogenic at all [44], have been already tested in many clinical trials for different pathologies [89-93]. In the best case scenario, MSCs therapy could retard the onset of irreversible lesions associated with metabolic syndrome or at least partially improve those already present in the organism. Also, the development of bioartificial implants such as in the way of a fat transplant (autologous, allogeneic, or even xenogeneic) could be envisioned [94-96]. This could be an innovative way to provide a new pool of MSCs to the patients [17, 97]; a permanent fat transplant such as the one proposed here could also be enriched with ex vivo expanded MSCs, or even those previously made differentiated into brown adipocytes, becoming in this way an immune privileged niche for the cotransplantation and implantation of different kind of allogeneic cells, tissues, and organs needed for the better functioning and regeneration of living organisms, without the danger of rejection or the need of prolonged administration of immunosuppressive drugs [44, 98-101]. Adipose tissue transplantation has primarily been used as a tool to study physiology and for human reconstructive surgery [102]. Transplantation of adipose tissue is, however, now being explored as a possible tool to promote the beneficial metabolic effects of subcutaneous white adipose tissue and brown adipose tissue, as well as adipose-derived stem cells [103]. Data suggest that the upregulation of brown adipose tissue activity can contribute to a lean and metabolically healthy phenotype in humans; these findings also suggest that the transplantation or stimulation of brown adipose tissue might be used as a therapeutic approach to increase energy expenditure and lower white adipose tissue mass and improve the overall metabolism, also is used as a potential induction of beneficial metabolic effects and treatment of diseases, such as obesity, lipodystrophy, or cardiovascular disease. As the amount of endogenous brown adipose tissue is very limited, identification and manipulation of critical regulators of brown adipose tissue differentiation have been used to engineer brown adipose tissue in order to induce beneficial effects [104, 105]. Ultimately, the clinical applicability of adipose tissue transplantation for the treatment of obesity and metabolic disorders will reside in the achievable level of safety, reliability and efficacy compared with other treatments [17]. In this way, cell therapy undoubtedly will be the most promising therapeutic strategy of this century not only for metabolic syndrome, but also probably for lipodystrophies, progeria, aging, and many other diseases [106-110]. Finally, beyond generating new pharmacological and natural healthy nutritional regimens, we should start thinking in the provocative frontiers of stem cell mechanisms that we must necessarily explore in order to decrease, in the next few years, the deleterious effects of the above-mentioned pathologies. If a "stem cell exhaustion syndrome" could be the cause of all these morbid states, we will surely be able to generate the best modalities to prevent and treat them. Also, may be defeating at last, the erroneous idea of irreversible aging.

\section{References}

[1] I. Saito, H. Iso, Y. Kokubo, M. Inoue, and S. Tsugane, "Metabolic syndrome and all-cause and cardiovascular disease mortality: Japan Public Health Center-based Prospective (JPHC) Study," Circulation Journal, vol. 73, no. 5, pp. 878884, 2009.

[2] P. Zimmet and G. Alberti, "The metabolic syndrome: progress towards one definition for an epidemic of our time," Nature Clinical Practice Endocrinology and Metabolism, vol. 4, no. 5, p. 239, 2008.

[3] G. M. Reaven, "The metabolic syndrome: requiescat in Pace," Clinical Chemistry, vol. 51, no. 6, pp. 931-938, 2005.

[4] M. A. Pappolla, T. K. Bryant-Thomas, D. Herbert et al., "Mild hypercholesterolemia is an early risk factor for the development of Alzheimer amyloid pathology," Neurology, vol. 61, no. 2, pp. 199-205, 2003.

[5] M. Junyent, R. Gilabert, E. Jarauta et al., "Impact of low-density lipoprotein receptor mutational class on carotid atherosclerosis in patients with familial hypercholesterolemia," Atherosclerosis, vol. 208, no. 2, pp. 437-441, 2010.

[6] R. Ceska, "Clinical implications of the metabolic syndrome," Diabetes and Vascular Disease Research, vol. 4, no. 3, pp. S2S4, 2007.

[7] P. Zimmet, D. Magliano, Y. Matsuzawa, G. Alberti, and J. Shaw, "The metabolic syndrome: a global public health problem and a new definition," Journal of Atherosclerosis and Thrombosis, vol. 12, no. 6, pp. 295-300, 2005.

[8] J. Capeau, "From lipodystrophy and insulin resistance to metabolic syndrome: HIV infection, treatment and aging," Current Opinion in HIV and AIDS, vol. 2, no. 4, pp. 247-252, 2007.

[9] P. W. Stacpoole, J. Alig, L. L. Kilgore et al., "Lipodystrophic diabetes mellitus. Investigations of lipoprotein metabolism and the effects of omega-3 fatty acid administration in two patients," Metabolism: Clinical and Experimental, vol. 37, no. 10, pp. 944-951, 1988. 
[10] J. Capeau, J. Magré, O. Lascols et al., "Diseases of adipose tissue: genetic and acquired lipodystrophies," Biochemical Society Transactions, vol. 33, no. 5, pp. 1073-1077, 2005.

[11] K. A. Lichtenstein, "Redefining lipodystrophy syndrome: risks and impact on clinical decision making," Journal of Acquired Immune Deficiency Syndromes, vol. 39, no. 4, pp. 395-400, 2005.

[12] V. Simha and A. Garg, "Inherited lipodystrophies and hypertriglyceridemia," Current Opinion in Lipidology, vol. 20, no. 4, pp. 300-308, 2009.

[13] J. Capeau, C. Vigouroux, J. Magré, O. Lascols, M. Caron, and J. P. Bastard, "Lipodystrophic syndromes: congenital or acquired diseases of adipose tissue," Comptes Rendus Biologies, vol. 329, no. 8, pp. 639-652, 2006.

[14] E. Urich, "Insulin resistance: the adipose tissue in the focus," Orvosi Hetilap, vol. 146, no. 43, pp. 2199-2207, 2005.

[15] S. Virtue and A. Vidal-Puig, "Adipose tissue expandability, lipotoxicity and the Metabolic Syndrome-an allostatic perspective," Biochimica et Biophysica Acta, vol. 1801, no. 3, pp. 338-349, 2010.

[16] E. Arner, P. O. Westermark, K. L. Spalding et al., "Adipocyte turnover: relevance to human adipose tissue morphology," Diabetes, vol. 59, no. 1, pp. 105-109, 2010.

[17] T. T. Tran and C. R. Kahn, "Transplantation of adipose tissue and stem cells: role in metabolism and disease," Nature Reviews Endocrinology, vol. 6, no. 4, pp. 195-213, 2010.

[18] S. Perrini, A. Cignarelli, R. Ficarella, L. Laviola, and F. Giorgino, "Human adipose tissue precursor cells: a new factor linking regulation of fat mass to obesity and type 2 diabetes?" Archives of Physiology and Biochemistry, vol. 115, no. 4, pp. 218-226, 2009.

[19] K. W. Park, D. S. Halperin, and P. Tontonoz, "Before they were fat: adipocyte progenitors," Cell Metabolism, vol. 8, no. 6, pp. 454-457, 2008.

[20] K. M. Hong, M. D. Burdick, R. J. Philips, D. Heber, and R. M. Strieter, "Characterization of human fibrocytes as circulating adipocyte progenitors and the formation of human adipose tissue in SCID mice," FASEB Journal, vol. 19, no. 14, pp. 2029-2031, 2005.

[21] S. Cinti, "Adipocyte differentiation and transdifferentiation: plasticity of the adipose organ," Journal of Endocrinological Investigation, vol. 25, no. 10, pp. 823-835, 2002.

[22] S. S. Tholpady, A. J. Katz, and R. C. Ogle, "Mesenchymal stem cells from rat visceral fat exhibit multipotential differentiation in vitro," Anatomical Record, Part A, vol. 272, no. 1, pp. 398-402, 2003.

[23] M. Laudes, "Role of WNT signalling in the determination of human mesenchymal stem cells into preadipocytes," Journal of Molecular Endocrinology, vol. 46, no. 2, pp. R65-R72, 2011.

[24] S. S. Hei, "Minireview: Pref-1: role in adipogenesis and mesenchymal cell fate," Molecular Endocrinology, vol. 23, no. 11, pp. 1717-1725, 2009.

[25] P. A. Zuk, M. Zhu, P. Ashjian et al., "Human adipose tissue is a source of multipotent stem cells," Molecular Biology of the Cell, vol. 13, no. 12, pp. 4279-4295, 2002.

[26] H. Mizuno, Y. Itoi, S. Kawahara, R. Ogawa, S. Akaishi, and H. Hyakusoku, "In vivo adipose tissue regeneration by adiposederived stromal cells isolated from GFP transgenic mice," Cells Tissues Organs, vol. 187, no. 3, pp. 177-185, 2008.

[27] C. Elabd, C. Chiellini, M. Carmona et al., "Human multipotent adipose-derived stem cells differentiate into functional brown adipocytes," Stem Cells, vol. 27, no. 11, pp. 2753-2760, 2009.
[28] W. Tang, D. Zeve, J. M. Suh et al., "White fat progenitor cells reside in the adipose vasculature," Science, vol. 322, no. 5901, pp. 583-586, 2008.

[29] S. M. Majka, K. E. Fox, J. C. Psilas et al., "De novo generation of white adipocytes from the myeloid lineage via mesenchymal intermediates is age, adipose depot, and gender specific," Proceedings of the National Academy of Sciences of the United States of America, vol. 107, no. 33, pp. 1478114786, 2010.

[30] T. J. Schulz, T. L. Huang, T. T. Tran et al., "Identification of inducible brown adipocyte progenitors residing in skeletal muscle and white fat," Proceedings of the National Academy of Sciences of the United States of America, vol. 108, no. 1, pp. 143-148, 2011.

[31] D. Langin, "Recruitment of brown fat and conversion of white into brown adipocytes: strategies to fight the metabolic complications of obesity?" Biochimica et Biophysica Acta, vol. 1801, no. 3, pp. 372-376, 2010.

[32] J. A. Timmons and B. K. Pedersen, "The importance of brown adipose tissue," New England Journal of Medicine, vol. 361, no. 4, pp. 415-416, 2009.

[33] H. A. Jacene and R. L. Wahl, "The importance of brown adipose tissue," New England Journal of Medicine, vol. 361, no. 4, pp. 417-418, 2009.

[34] D. L. Morganstein, P. Wu, M. R. Mane, N. M. Fisk, R. White, and M. G. Parker, "Human fetal mesenchymal stem cells differentiate into brown and white adipocytes: a role for ERR $\alpha$ in human UCP1 expression," Cell Research, vol. 20, no. 4, pp. 434-444, 2010.

[35] S. Shah, J. Ulm, Z. C. Sifri, A. M. Mohr, and D. H. Livingston, "Mobilization of bone marrow cells to the site of injury is necessary for wound healing," Journal of Trauma, vol. 67, no. 2, pp. 315-321, 2009.

[36] T. Glaros, M. Larsen, and L. Li, "Macrophages and fibroblasts during inflammation, tissue damage and organ injury," Frontiers in Bioscience, vol. 14, pp. 3988-3993, 2009.

[37] I. Jialal, G. P. Fadini, K. Pollock, and S. Devaraj, "Circulating levels of endothelial progenitor cell mobilizing factors in the metabolic syndrome," American Journal of Cardiology, vol. 106, no. 11, pp. 1606-1608, 2010.

[38] G. L. Hoetzer, G. P. Van Guilder, H. M. Irmiger, R. S. Keith, B. L. Stauffer, and C. A. DeSouza, "Aging, exercise, and endothelial progenitor cell clonogenic and migratory capacity in men," Journal of Applied Physiology, vol. 102, no. 3, pp. 847-852, 2007.

[39] G. P. Fadini, S. V. De Kreutzenberg, A. Coracina et al., "Circulating CD $34^{+}$cells, metabolic syndrome, and cardiovascular risk," European Heart Journal, vol. 27, no. 18, pp. 2247-2255, 2006.

[40] C. M. Kolf, E. Cho, and R. S. Tuan, "Mesenchymal stromal cells. Biology of adult mesenchymal stem cells: regulation of niche, self-renewal and differentiation," Arthritis Research and Therapy, vol. 9, no. 1, article no. 204, 2007.

[41] Y. Shi, G. Hu, J. Su et al., "Mesenchymal stem cells: a new strategy for immunosuppression and tissue repair," Cell Research, vol. 20, no. 5, pp. 510-518, 2010.

[42] S. W. Qian, XI. Li, Y. Y. Zhang et al., "Characterization of adipocyte differentiation from human mesenchymal stem cells in bone marrow," BMC Developmental Biology, vol. 10, article no. 47, 2010.

[43] C. De Bari, F. Dell'Accio, J. Vanlauwe et al., "Mesenchymal multipotency of adult human periosteal cells demonstrated 
by single-cell lineage analysis," Arthritis and Rheumatism, vol. 54, no. 4, pp. 1209-1221, 2006.

[44] E. Mansilla, H. Drago, G. H. Marin, F. Sturla, R. Ibar, and C. Soratti, "Mesenchymal stem cells, could they be the link between tolerance and regeneration?" Burns, vol. 33, no. 2, pp. 137-138, 2007.

[45] J. A. Kode, S. Mukherjee, M. V. Joglekar, and A. A. Hardikar, "Mesenchymal stem cells: immunobiology and role in immunomodulation and tissue regeneration," Cytotherapy, vol. 11, no. 4, pp. 377-391, 2009.

[46] C. A. Gregory, J. Ylostalo, and D. J. Prockop, "Adult bone marrow stem/progenitor cells (MSCs) are preconditioned by microenvironmental "niches" in culture: a two-stage hypothesis for regulation of MSC fate," Science's STKE, vol. 2005, no. 294, p. pe37, 2005.

[47] N. Carlesso and A. A. Cardoso, "Stem cell regulatory niches and their role in normal and malignant hematopoiesis," Current Opinion in Hematology, vol. 17, no. 4, pp. 281-286, 2010.

[48] Z. Zhong, A. N. Patel, T. E. Ichim et al., "Feasibility investigation of allogeneic endometrial regenerative cells," Journal of Translational Medicine, vol. 7, article no. 15, 2009.

[49] G. Q. Jia, M. M. Zhang, P. Yang, J. Q. Cheng, Y. R. Lu, and X. T. Wu, "Effects of the different culture and isolation methods on the growt, Proliferation and biology characteristics of rat bone marrow mesenchymal stem cells," Sichuan Da Xue Xue Bao Yi Xue Ban, vol. 40, no. 4, pp. 719-723, 2009.

[50] L. da Silva Meirelles, P. C. Chagastelles, and N. B. Nardi, "Mesenchymal stem cells reside in virtually all post-natal organs and tissues," Journal of Cell Science, vol. 119, no. 11, pp. 2204-2213, 2006.

[51] A. Chapel, J. M. Bertho, M. Bensidhoum et al., "Mesenchymal stem cells home to injured tissues when co-infused with hematopoietic cells to treat a radiation-induced multi-organ failure syndrome," Journal of Gene Medicine, vol. 5, no. 12, pp. 1028-1038, 2003.

[52] E. Mansilla, G. H. Marín, H. Drago et al., "Bloodstream cells phenotypically identical to human mesenchymal bone marrow stem cells circulate in large amounts under the influence of acute large skin damage: new evidence for their use in regenerative medicine," Transplantation Proceedings, vol. 38, no. 3, pp. 967-969, 2006.

[53] H. Hemeda, M. Jakob, A. K. Ludwig, B. Giebel, S. Lang, and S. Brandau, "Interferon- $\gamma$ and tumor necrosis factor$\alpha$ differentially affect cytokine expression and migration properties of mesenchymal stem cells," Stem Cells and Development, vol. 19, no. 5, pp. 693-706, 2010.

[54] N. Barbarroja, R. López-Pedrera, M. D. Mayas et al., "The obese healthy paradox: is inflammation the answer?" Biochemical Journal, vol. 430, no. 1, pp. 141-149, 2010.

[55] A. A. Rizvi, "Hypertension, obesity, and inflammation: the complex designs of a deadly trio," Metabolic Syndrome and Related Disorders, vol. 8, no. 4, pp. 287-294, 2010.

[56] B. G. Gálvez, N. San Martín, and C. Rodríguez, “TNF-alpha is required for the attraction of mesenchymal precursors to white adipose tissue in Ob/ob mice," PLoS One, vol. 4, no. 2, article e4444, 2009.

[57] M. J. Peterson, M. C. Morey, C. Giuliani et al., "Walking in old age and development of metabolic syndrome: the health, aging, and body composition study," Metabolic Syndrome and Related Disorders, vol. 8, no. 4, pp. 317-322, 2010.

[58] E. V. Tereshina, "Metabolic abnormalities as a basis for agedependent diseases and aging? State of the art," Advances in Gerontology, vol. 22, no. 1, pp. 129-138, 2009.
[59] J. Halaschek-Wiener and A. Brooks-Wilson, "Progeria of stem cells: stem cell exhaustion in Hutchinson-Gilford progeria syndrome," Journals of Gerontology. Series A, vol. 62, no. 1, pp. 3-8, 2007.

[60] J. Mazereeuw-Hautier, L. C. Wilson, S. Mohammed et al., "Hutchinson-Gilford progeria syndrome: clinical findings in three patients carrying the G608G mutation in LMNA and review of the literature," British Journal of Dermatology, vol. 156, no. 6, pp. 1308-1314, 2007.

[61] H. D. M. Coutinho, V. S. Falcão-Silva, and G. F. Gonçalves, "Hutchinson-gilford progeria syndrome: clinical and genetical traits," Panminerva Medica, vol. 51, no. 2, pp. 134-135, 2009.

[62] I. Russo-Menna and C. Arancibias, "The Hutchinson-Gilford Progeria Syndrome: a case report," Minerva Anestesiologica, vol. 76, no. 2, pp. 151-154, 2010.

[63] H. D. M. Coutinho, V. S. Falcão-Silva, G. Gonçalves, and R. da Nóbrega, "Molecular ageing in progeroid syndromes: Hutchinson-Gilford progeria syndrome as a model," Immunity and Ageing, vol. 6, article no. 4, 2009.

[64] M. A. Merideth, L. B. Gordon, S. Clauss et al., "Phenotype and course of Hutchinson-Gilford progeria syndrome," New England Journal of Medicine, vol. 358, no. 6, pp. 592-604, 2008.

[65] K. N. Dahl, P. Scaffidi, M. F. Islam, A. G. Yodh, K. L. Wilson, and T. Misteli, "Distinct structural and mechanical properties of the nuclear lamina in Hutchinson-Gilford progeria syndrome," Proceedings of the National Academy of Sciences of the United States of America, vol. 103, no. 27, pp. 10271-10276, 2006.

[66] J. Candelario, S. Sudhakar, S. Navarro, S. Reddy, and L. Comai, "Perturbation of wild-type lamin A metabolism results in a progeroid phenotype," Aging Cell, vol. 7, no. 3, pp. 355-367, 2008.

[67] P. Scaffidi and T. Misteli, "Lamin A-dependent misregulation of adult stem cells associated with accelerated ageing," Nature Cell Biology, vol. 10, no. 4, pp. 452-459, 2008.

[68] J. L. V. Broers, F. C. S. Ramaekers, G. Bonne, R. Ben Yaou, and C. J. Hutchison, "Nuclear lamins: laminopathies and their role in premature ageing," Physiological Reviews, vol. 86, no. 3, pp. 967-1008, 2006.

[69] E. Fuchs, "The tortoise and the hair: slow-cycling cells in the stem cell race," Cell, vol. 137, no. 5, pp. 811-819, 2009.

[70] J. M. Bridger and I. R. Kill, "Aging of HutchinsonGilford progeria syndrome fibroblasts is characterised by hyperproliferation and increased apoptosis," Experimental Gerontology, vol. 39, no. 5, pp. 717-724, 2004.

[71] J. W. Hou, "Natural course of neonatal progeroid syndrome," Pediatrics and Neonatology, vol. 50, no. 3, pp. 102-109, 2009.

[72] S. L. Ding and C. Y. Shen, "Model of human aging: recent findings on Werner's and Hutchinson-Gilford progeria syndromes," Clinical Interventions in Aging, vol. 3, no. 3, pp. 431444, 2008.

[73] W. B. Ershler, L. Ferrucci, and D. L. Longo, "HutchinsonGilford progeria syndrome," New England Journal of Medicine, vol. 358, no. 22, pp. 2409-2410, 2008.

[74] B. Korf, "Focus on research: Hutchinson-Gilford progeria syndrome, aging, and the nuclear lamina," New England Journal of Medicine, vol. 358, no. 6, pp. 552-554, 2008.

[75] R. S. C. Friedman and D. S. Krause, "Regeneration and repair: new findings in stem cell research and aging," Annals of the New York Academy of Sciences, vol. 1172, pp. 88-94, 2009. 
[76] K. E. Wellen and G. S. Hotamisligil, "Inflammation, stress, and diabetes," Journal of Clinical Investigation, vol. 115, no. 5, pp. 1111-1119, 2005.

[77] B. Gustafson, A. Hammarstedt, C. X. Andersson, and U. Smith, "Inflamed adipose tissue: a culprit underlying the metabolic syndrome and atherosclerosis," Arteriosclerosis, Thrombosis, and Vascular Biology, vol. 27, no. 11, pp. 22762283, 2007.

[78] I. Bellantuono, A. Aldahmash, and M. Kassem, "Aging of marrow stromal (skeletal) stem cells and their contribution to age-related bone loss," Biochimica et Biophysica Acta, vol. 1792, no. 4, pp. 364-370, 2009.

[79] O. Naveiras, V. Nardi, P. L. Wenzel, P. V. Hauschka, F. Fahey, and G. Q. Daley, "Bone-marrow adipocytes as negative regulators of the haematopoietic microenvironment," Nature, vol. 460, no. 7252, pp. 259-263, 2009.

[80] A. Dunac, C. Frelin, M. Popolo-Blondeau, M. Chatel, M. H. Mahagne, and P. J. M. Philip, "Neurological and functional recovery in human stroke are associated with peripheral blood CD34+ cell mobilization," Journal of Neurology, vol. 254, no. 3, pp. 327-332, 2007.

[81] V. L. T. Ballard and J. M. Edelberg, "Stem cells and the regeneration of the aging cardiovascular system," Circulation Research, vol. 100, no. 8, pp. 1116-1127, 2007.

[82] N. A. Mikirova, J. A. Jackson, R. Hunninghake et al., "Nutraceutical augmentation of circulating endothelial progenitor cells and hematopoietic stem cells in human subjects," Journal of Translational Medicine, vol. 8, article no. 34, 2010.

[83] G. S. Jensen, A. N. Hart, L. A. M. Zaske et al., "Mobilization of human $\mathrm{CD} 34^{+} \mathrm{CD} 133^{+}$and $\mathrm{CD} 34^{+} \mathrm{CD} 133^{-}$stem cells in vivo by consumption of an extract from Aphanizomenon flosaquae-related to modulation of CXCR4 expression by an Lselectin ligand?" Cardiovascular Revascularization Medicine, vol. 8, no. 3, pp. 189-202, 2007.

[84] T. E. Ichim, Z. Zhong, N. A. Mikirova et al., "Circulating endothelial progenitor cells and erectile dysfunction: possibility of nutritional intervention?" Panminerva medica, vol. 52, no. 2, supplement 1, pp. 75-80, 2010.

[85] S. Erbs, R. Höllriegel, A. Linke et al., "Exercise training in patients with advanced chronic heart failure (NYHA IIIb) promotes restoration of peripheral vasomotor function, induction of endogenous regeneration, and improvement of left ventricular function," Circulation: Heart Failure, vol. 3, no. 4, pp. 486-494, 2010.

[86] T. Kondo, M. Hayashi, K. Takeshita et al., "Smoking cessation rapidly increases circulating progenitor cells in peripheral blood in chronic smokers," Arteriosclerosis, Thrombosis, and Vascular Biology, vol. 24, no. 8, pp. 1442-1447, 2004.

[87] C. Fiorito, M. Rienzo, E. Crimi et al., "Antioxidants increase number of progenitor endothelial cells through multiple gene expression pathways," Free Radical Research, vol. 42, no. 8, pp. 754-762, 2008.

[88] L. Xia, X. X. Wang, X. S. Hu et al., "Resveratrol reduces endothelial progenitor cells senescence through augmentation of telomerase activity by Akt-dependent mechanisms," British Journal of Pharmacology, vol. 155, no. 3, pp. 387-394, 2008.

[89] P. Menasché, O. Alfieri, S. Janssens et al., "The myoblast autologous grafting in ischemic cardiomyopathy (MAGIC) trial: first randomized placebo-controlled study of myoblast transplantation," Circulation, vol. 117, no. 9, pp. 1189-1200, 2008.
[90] M. Yousef, C. M. Schannwell, M. Köstering, T. Zeus, M. Brehm, and B. E. Strauer, "The BALANCE Study: clinical benefit and long-term outcome after intracoronary autologous bone marrow cell transplantation in patients with acute myocardial infarction," Journal of the American College of Cardiology, vol. 53, no. 24, pp. 2262-2269, 2009.

[91] J. M. Gimble, A. J. Katz, and B. A. Bunnell, "Adipose-derived stem cells for regenerative medicine," Circulation Research, vol. 100, no. 9, pp. 1249-1260, 2007.

[92] J. O. Beitnes, E. Hopp, K. Lunde et al., "Long-term results after intracoronary injection of autologous mononuclear bone marrow cells in acute myocardial infarction: the ASTAMI randomised, controlled study," Heart, vol. 95, no. 24, pp. 1983-1989, 2009.

[93] G. P. Meyer, K. C. Wollert, J. Lotz et al., "Intracoronary bone marrow cell transfer after myocardial infarction: eighteen months' follow-up data from the randomized, controlled BOOST (Bone marrow transfer to enhance ST-elevation infarct regeneration) trial," Circulation, vol. 113, no. 10, pp. 1287-1294, 2006.

[94] T. T. Tran, Y. Yamamoto, S. Gesta, and C. R. Kahn, "Beneficial effects of subcutaneous fat transplantation on metabolism," Cell Metabolism, vol. 7, no. 5, pp. 410-420, 2008.

[95] S. Klebanov, C. M. Astle, O. DeSimone, V. Ablamunits, and D. E. Harrison, "Adipose tissue transplantation protects ob/ob mice from obesity, normalizes insulin sensitivity and restores fertility," Journal of Endocrinology, vol. 186, no. 1, pp. 203-211, 2005.

[96] S. R. Coleman, "Long-term survival of fat transplants: controlled demonstrations," Aesthetic Plastic Surgery, vol. 19, no. 5, pp. 421-425, 1995.

[97] P. Bauer-Kreisel, A. Goepferich, and T. Blunk, "Cell-delivery therapeutics for adipose tissue regeneration," Advanced Drug Delivery Reviews, vol. 62, no. 7-8, pp. 798-813, 2010.

[98] S. Caspar-Bauguil, B. Cousin, A. Galinier et al., "Adipose tissues as an ancestral immune organ: site-specific change in obesity," FEBS Letters, vol. 579, no. 17, pp. 3487-3492, 2005.

[99] B. Puissant, C. Barreau, P. Bourin et al., "Immunomodulatory effect of human adipose tissue-derived adult stem cells: comparison with bone marrow mesenchymal stem cells," British Journal of Haematology, vol. 129, no. 1, pp. 118-129, 2005.

[100] R. Yañez, M. L. Lamana, J. García-Castro, I. Colmenero, M. Ramírez, and J. A. Bueren, "Adipose tissue-derived mesenchymal stem cells have in vivo immunosuppressive properties applicable for the control of the graft-versus-host disease," Stem Cells, vol. 24, no. 11, pp. 2582-2591, 2006.

[101] K. Le Blanc and O. Ringdén, "Immunomodulation by mesenchymal stem cells and clinical experience," Journal of Internal Medicine, vol. 262, no. 5, pp. 509-525, 2007.

[102] K. Yoshimura, K. Sato, N. Aoi, M. Kurita, T. Hirohi, and K. Harii, "Cell-assisted lipotransfer for cosmetic breast augmentation: supportive use of adipose-derived stem/stromal cells," Aesthetic Plastic Surgery, vol. 32, no. 1, pp. 48-55, 2008.

[103] E. L. Lacy and T. J. Bartness, "Effects of white adipose tissue grafts on total body fat and cellularity are dependent on graft type and location," American Journal of Physiology, vol. 289, no. 2, pp. R380-R388, 2005.

[104] G. Dellagiacoma, A. Sbarbati, M. Rossi et al., "Brown adipose tissue: magnetic resonance imaging and ultrastructural studies after transplantation in syngeneic rats," Transplantation Proceedings, vol. 24, no. 6, p. 2986, 1992. 
[105] L. Ferren, "Morphological differentiation of implanted brown and white fats," Transactions of the Kansas Academy of Science, vol. 69, no. 1, pp. 350-353, 1966.

[106] A. Garg and A. K. Agarwal, "Lipodystrophies: disorders of adipose tissue biology," Biochimica et Biophysica Acta, vol. 1791, no. 6, pp. 507-513, 2009.

[107] O. Gavrilova, B. Marcus-Samuels, D. Graham et al., "Surgical implantation of adipose tissue reverses diabetes in lipoatrophic mice," Journal of Clinical Investigation, vol. 105, no. 3, pp. 271-278, 2000.

[108] D. M. Huffman and N. Barzilai, "Role of visceral adipose tissue in aging," Biochimica et Biophysica Acta, vol. 1790, no. 10, pp. 1117-1123, 2009.

[109] R. Muzumdar, D. B. Allison, D. M. Huffman et al., "Visceral adipose tissue modulates mammalian longevity," Aging Cell, vol. 7, no. 3, pp. 438-440, 2008.

[110] D. M. Huffman and N. Barzilai, "Contribution of adipose tissue to health span and longevity," Interdisciplinary Topics in Gerontology, vol. 37, pp. 1-19, 2010. 

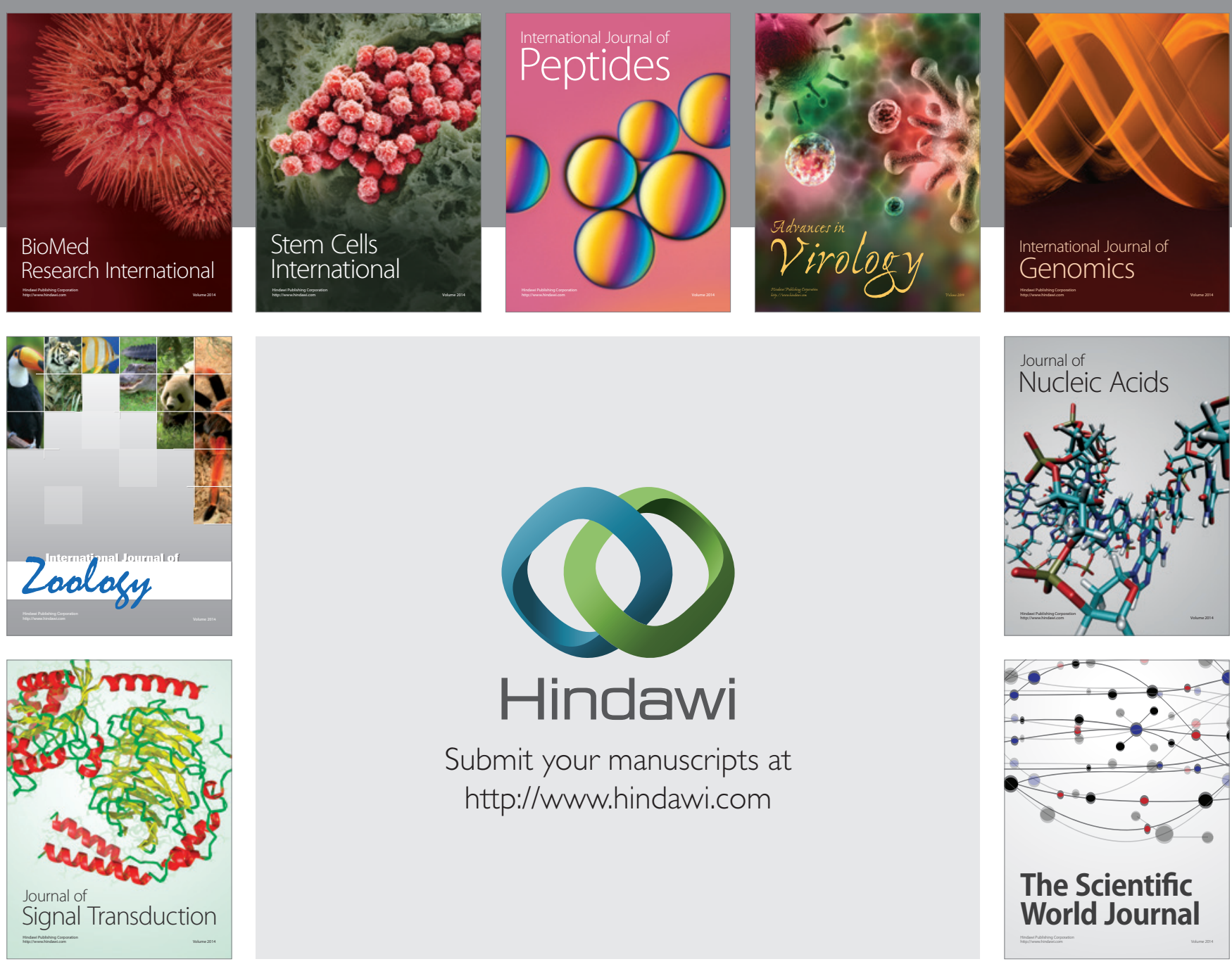

Submit your manuscripts at

http://www.hindawi.com
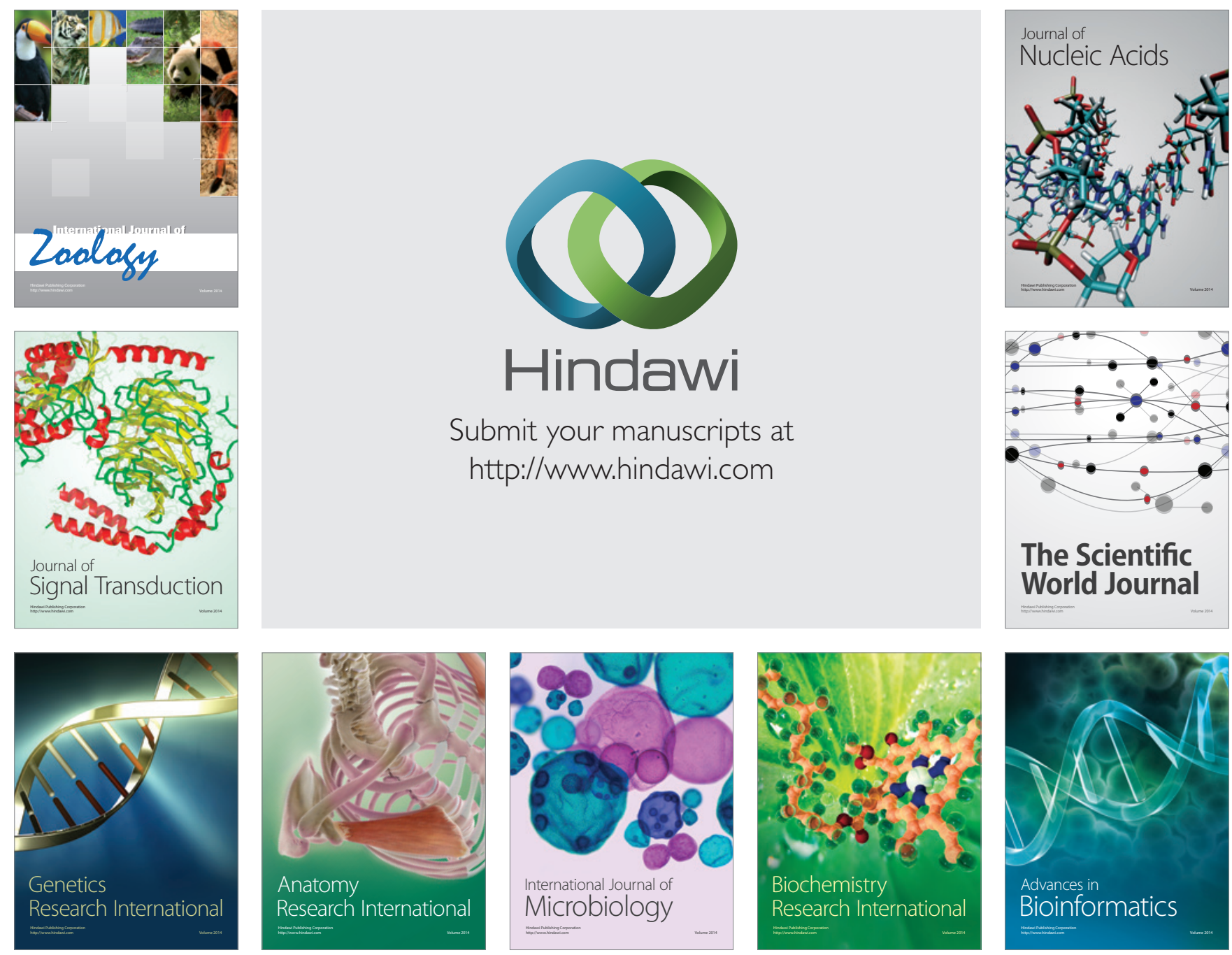

The Scientific World Journal
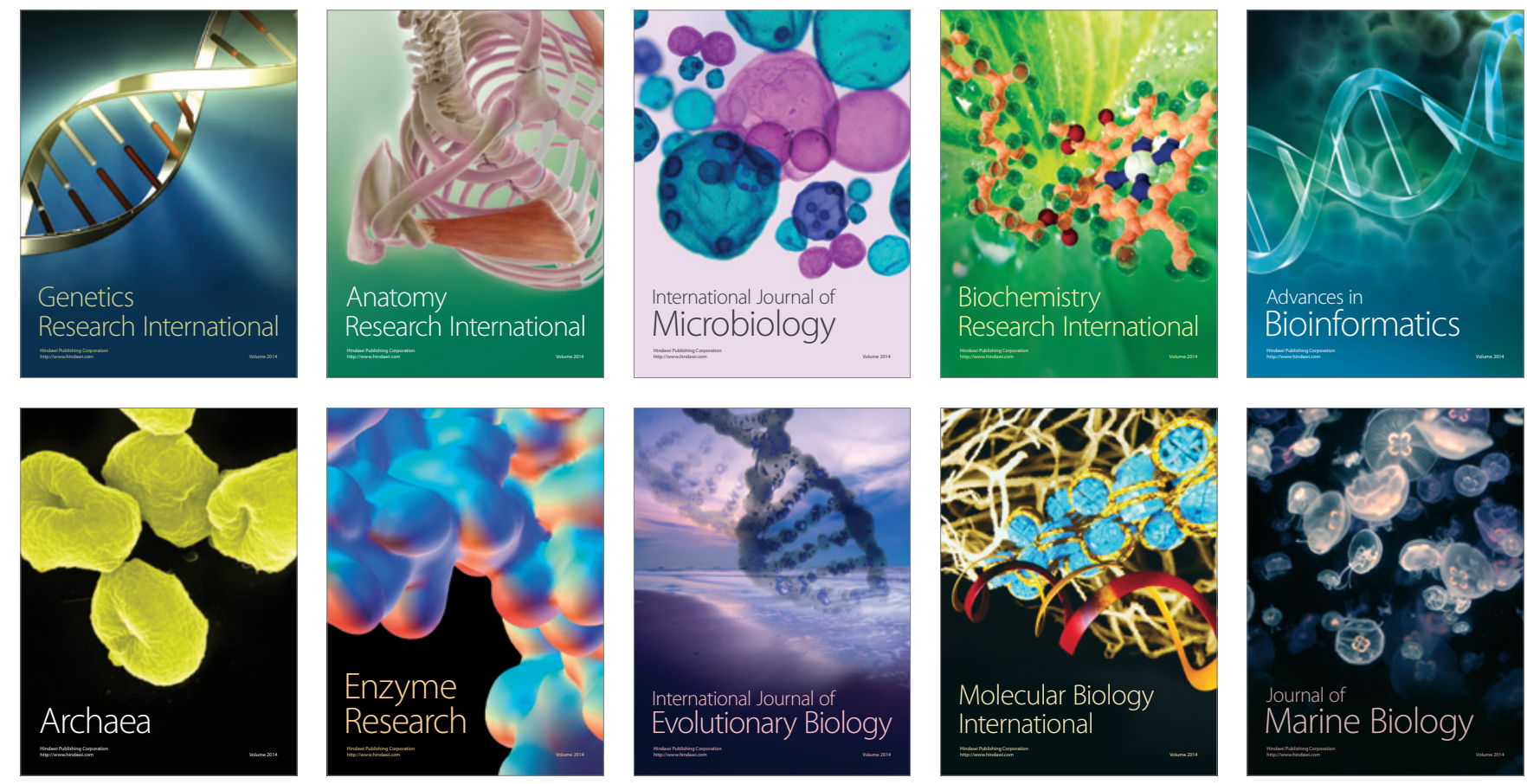